\title{
Laser Production of Highly Charged Ions
}

\author{
L. Láska ${ }^{1}$, J. Badziak ${ }^{2}$, F.P. Boody ${ }^{3}$, S. Gammino ${ }^{4}$, K. Jungwirth ${ }^{1}$, J. Krása ${ }^{1}$, M. Pfeifer ${ }^{1}$, \\ K. Rohlena ${ }^{1}$, J. Ullschmied ${ }^{1}$, P. Parys ${ }^{2}$, J. Wołowski $^{2}, \dagger$ E. Woryna ${ }^{2}$, and L. Torrisi ${ }^{4,5}$ \\ ${ }^{1}$ Institute of Physics, A.S.C.R., Na Slovance 2, 18221 Prague 8, Czech Republic \\ ${ }^{2}$ Institute of Plasma Physics and Laser Microfusion, Hery St. 23, 00-908 Warsaw, Poland \\ ${ }^{3}$ Ion Light Technologies GmbH, 93077 Bad Abbach, Germany \\ ${ }^{4}$ INFN - Laboratori Nazionali del Sud, Via S. Sofia 44, 95123 Catania, Italy \\ ${ }^{5}$ Universita di Messina, Ctr. Papardo-Sperone, 31, 98166 S. Agata, Messina, Italy
}

Received on 15 January, 2004; revised version received on 3 May, 2004

\begin{abstract}
A summary of ion generation experiments at both low $\left(10^{9} \mathrm{~W} / \mathrm{cm}^{2}\right)$ and high $\left(10^{16} \mathrm{~W} / \mathrm{cm}^{2}\right)$ laser intensities, using Nd:YAG and iodine lasers, as well as the properties of the ions produced, are presented. Different medium- and high- $\mathrm{Z}$ elements were tested as a target: $\mathrm{Ag}, \mathrm{Al}, \mathrm{Au}, \mathrm{Co}, \mathrm{Cu}, \mathrm{Nb}, \mathrm{Ni}, \mathrm{Pb}, \mathrm{Pt}, \mathrm{Sn}, \mathrm{Ta}$, W. A maximum charge state 55+ and maximum energy $34 \mathrm{MeV}$ were recorded for Ta ions at high laser intensities, while the charge states up to $10+$ and energies lower than $10 \mathrm{keV}$ are characteristic for the region of low limit intensities. At laser intensities above $2 \times 10^{14} \mathrm{~W} / \mathrm{cm}^{2}$ conditions for the presence of nonlinear processes are fulfilled and ion acceleration due to ponderomotive force appears, in addition to the thermal and hot electron guided ambipolar acceleration. The existence of two production mechanisms for highly charged ions with charge states above $\mathrm{z}=50+$ has been demonstrated by changing the minimum focus position with regard to the target surface (by changing the interaction length with pre-formed plasma for relativistic self-focusing). Various potential applications of LIS are mentioned
\end{abstract}

\section{Introduction}

There is no doubt at present that Laser Ion Sources (LIS) are the most efficient sources of highly charged ions. Depending on the type of laser used and its parameters, ions with charge states from $1+$ up to more than $50+$ can be produced, with ion energies ranging from hundreds of $\mathrm{eV}$ up to hundreds of $\mathrm{MeV}$. The higher the laser intensity, the higher the charge states and the energy of the ions generated. The ion current density, $j$, may attain of $\mathrm{mA} / \mathrm{cm}^{2}$ at a distance of $1 \mathrm{~m}$ from the target $\left(j>10 \mathrm{kA} / \mathrm{cm}^{2}\right.$ near the target) [1]. Highly charged heavy ions $\left(\mathrm{Pb}^{25+}\right)$ required for the preinjector of Large Hadron Collider (LHC) at CERN in Geneva (ions with charge state above 53+, considered for preinjectors of second generation, would save one stripper, where the lost of ions is about $80 \%$, at present) and $\mathrm{Co}^{25+}$ ions are needed for Terra Watt Accumulator (TWAC) at ITEP in Moscow [2-4]. Low charge state ions with energies of hundreds eV only are considered for the new hybrid ion source ECLISSE (ECR ion source Coupled to LIS for charge State Enhancement $[5,6])$ that should combine the best properties of LIS and ECRIS. On the contrary, ions with high energy (up to $\mathrm{MeV}$ without external acceleration) can be used for ion implantation [7-10] to modify surface properties of solid materials. Interest in Laser Space Propulsion, particularly using laser ablated plasmas, has been revived quite recently [11]. Most applications of LIS are based on production of a large number of ions. Thus, lasers with high repetition rate are preferred for applications, while single shot lasers are used mainly for fundamental studies.

Various lasers have been used for experiments in the authors' laboratories aimed at producing different kinds of ions. Maximum ion charge states $z=55+$ have been recorded, as well as the maximum energy of emitted ions $E_{i}=34 \mathrm{MeV}$. The most important (typical) results and dependencies (both the older and the new ones) are summarized. All the presented experiments serve as a basis for wide discussions of various alternative, but not yet unambiguously determined, mechanisms of ion production and acceleration.

\section{Experimental arrangement and ion diagnostics}

To study ion production at low laser power densities, a Nd:YAG laser (LAB-190, Spectra Physics-Quanta Ray) with a nominal energy of $900 \mathrm{~mJ}$ in a $9 \mathrm{~ns}$ long pulse was used in our experiments at INFN LNS, Catania. The laser beam was focused using lenses of different focal length (mainly $500 \mathrm{~mm}$ ) onto the target, which was located in an interaction chamber evacuated to about $6 \times 10^{-7} \mathrm{mbar}$. The minimum focal spot was found to be smaller than $0.5 \mathrm{~mm}$ in diameter. Its area varied due to different distances of the lens from the target, different incidence angles of the beam on the target, and the dependence of the laser beam diver- 
gence on the laser pumping energy. A schematic view of the experimental arrangement is presented elsewhere [5].

Two high-power photodissociation iodine laser systems PERUN $\left(\lambda=1.315 \mu \mathrm{m}, E_{L} \sim 50 \mathrm{~J}, \tau \sim 350 \mathrm{ps}\right.$, $\left.I_{L} \sim 1.5 \times 10^{15} \mathrm{~W} / \mathrm{cm}^{2}\right)[12]$ and PALS $\left(E_{L} \sim 1 \mathrm{~kJ}\right.$, $\tau \sim 400 \mathrm{ps}, I_{L} \sim 6 \times 10^{16} \mathrm{~W} / \mathrm{cm}^{2}$ ) [13], located at IP ASCR and at the PALS Research Center in Prague, were used to generate highly charged ions of several medium$\mathrm{Z}$ and high- $\mathrm{Z}$ elements. After the frequency conversion in DKDP crystals, the lasers could be operated at the second $(\lambda / 2=0.657 \mu \mathrm{m})$ and/or the third $(\lambda / 3=0.438 \mu \mathrm{m})$ harmonic frequency with efficiency up to $50 \%$. Targets were irradiated obliquely $\left(30^{\circ}\right.$ with respect to the target normal) or normally with regard to the incident laser beam. The $29-\mathrm{cm}$ diameter beam of laser PALS was focused with an aspherical lens onto the targets with a minimum focal spot diameter of $70 \mu \mathrm{m}$. A sketch of the experimental arrangement is shown in Fig. 1.

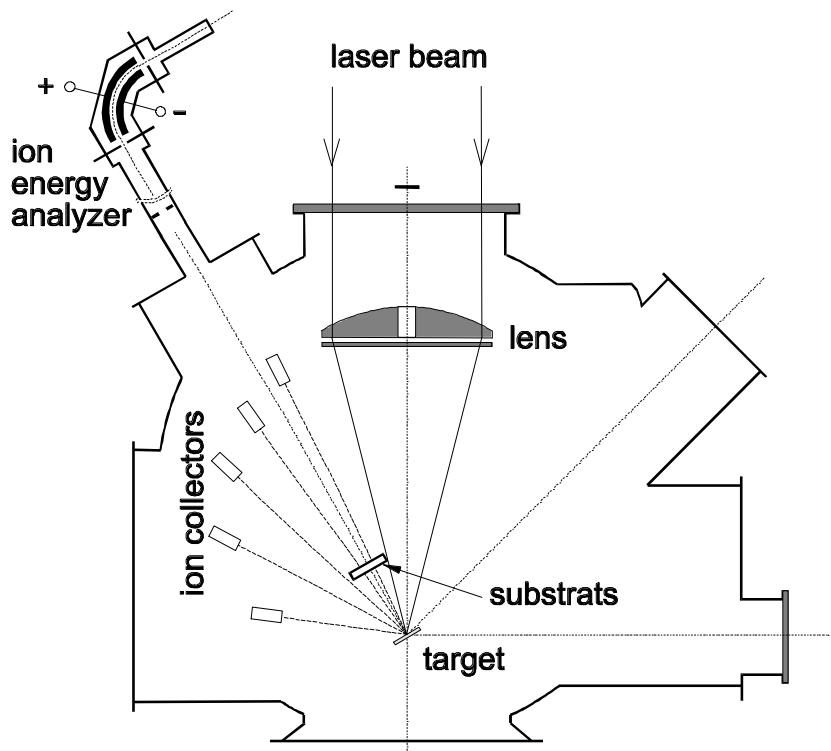

Figure 1. Sketch of the PALS target chamber experimental arrangement.

The principal diagnostic techniques used for analysis of the properties of the laser-produced plasma were based on the time-of-flight method (ion collectors, IC) or on time offlight combined with a superimposed electric and/or magnetic field (cylindrical electrostatic ion energy analyzer, IEA, and Thomson parabola spectrometer, TPS, [12,14]). Generally, the charge-integrated time-resolved IC signals show distinct, more or less pronounced, maxima, whose position and amplitude reflect not only the mechanisms of ion production and acceleration, but also variations of laser parameters: laser pulse divergence, radial inhomogeneities, spikes, prepulses, etc. From the IC signals, the peak and mean (and/or maximum) ion velocities and energies, as well as ion current densities can be evaluated (estimated).

The IEA makes it possible to identify the ion species produced, i.e. to determine their mass-to-charge ratios, energies and abundance. Charge-energy distribution is obtained by varying the voltage on the electrode plates of the analyzer from shot to shot at fixed experimental conditions. Using the TPS it is possible to distinguish different ions with the same $m / z$ ratio, as well as to record their velocity (energy) distribution in a single laser shot. Although the TPS has a low dynamic range and a low mass-resolution for energetic and highly charged heavy ions, it can provide complete and quick information on the ion species and on the underlying physical processes in the plasma.

Quantitative results can be distorted by the kind of ion detector used (ion collector, windowless electron multiplier, microchannel plate). One of the problems is connected with the electron yield, $\gamma$, of the electron emission induced by the impact of ions on the detector surface. The value of $\gamma$ depends on the ion charge state $z$, ion energy $E_{i}$, and the detectors surface quality. The $\gamma$ increases with the charge state of the impinging ions, for fixed ion kinetic energy, and, for fixed $z$, it has a minimum in its variation with $E_{i}$. Thus, the value of $\gamma / z$ (needed for evaluation of ion current) ranges from $\sim 0.3$ to $\sim 3.5$, depending on the charge state and kinetic energy of the ion; the lower the energy, the larger the spread of $\gamma / z[15,16]$.

\section{Results and discussion}

The yields and properties of $\mathrm{Al}, \mathrm{Au}, \mathrm{Cu}, \mathrm{Nb}, \mathrm{Ni}, \mathrm{Pb}$, $\mathrm{Sn}$, Ta and $\mathrm{W}$ ions from plasma produced by the $0.9-\mathrm{J} / 9-$ ns Nd:YAG laser have been previously reported e.g. in $[5,17,18]$. By changing either the laser pulse energy or the focal spot size, the laser intensity on the target surface was varied from $1 \times 10^{9}$ to about $1 \times 10^{11} \mathrm{~W} / \mathrm{cm}^{2}$, i.e. from the threshold power density for ion generation up to the maximum laser intensities attainable with the setup used. The ion velocities (ion energies) ranged from about $2 \times 10^{6}$ to $2 \times 10^{7} \mathrm{~cm} / \mathrm{s}(100 \mathrm{eV}-10 \mathrm{keV})$ depending on the target element used and on the laser intensity. The ion emission was peaked along the normal to the target surface; the angular distribution of ions shows a strong anisotropy and it was not the same for all the elements studied. The relative steepness of the distribution with respect to the target normal is given by [19]

$$
d N / d \Omega=\Sigma d N_{z} / d \Omega=\Sigma b_{z} \cos ^{n_{Z}}(\varphi)
$$

where $b_{z}$ is the charge state distribution, which depends on the plasma ion temperature (which, in turn, depends on the laser intensity), and $n_{z}$ depends strongly on the ion mass $A$, and less on the charge state $z$. From all the elements studied the narrowest distribution was recorded for $\mathrm{W}$ and the widest for $\mathrm{Al}$ and $\mathrm{Ni}$ (see Fig. 2). The recorded ion current densities ranged from $4 \mathrm{~mA} / \mathrm{cm}^{2}$ (for $\mathrm{Au}$ ) to $43 \mathrm{~mA} / \mathrm{cm}^{2}$ (for $\mathrm{Cu})$ at a distance of $44 \mathrm{~cm}$ from the target. Charge spectra of $\mathrm{Au}, \mathrm{Nb}, \mathrm{Ta}, \mathrm{Pb}$ and $\mathrm{W}$ were measured at $E_{L} \sim 40 \mathrm{~mJ}$ and $E_{L} \sim 300 \mathrm{~mJ}$, respectively, from which the charge-state distributions (CSD) and the charge-energy distributions (CED) were evaluated. The abundance of $\mathrm{W}$ ions produced at these two laser energies is compared in Fig. 3, as an example. The majority (about 70\%) of emitted particles, at the laser intensities used, consisted of neutrals [17]. The proportion of 
ions (with respect to neutrals), as well as the presence of the highest charge state, increases with the increasing laser intensity. The maximum recorded charge state was $10+$ at our experimental conditions. The charge state was lower than $4+$ for more than $70 \%$ of the ions for all elements tested.
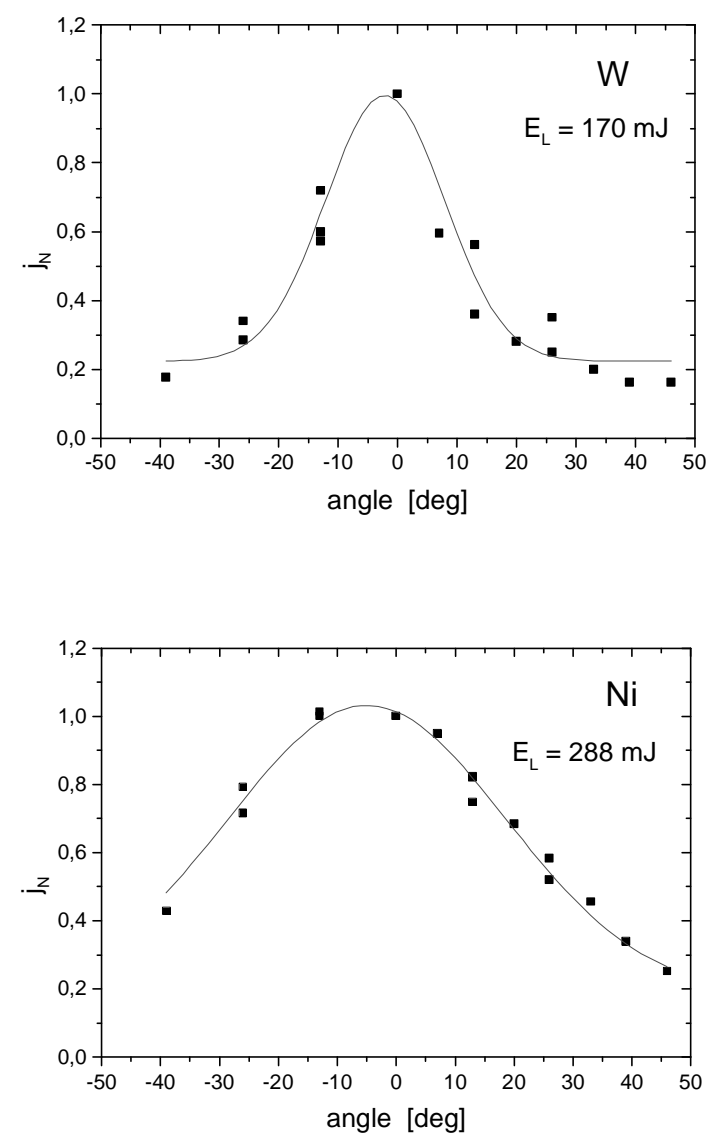

Figure 2. Angular distribution of $\mathrm{W}$ and $\mathrm{Ni}$ ions, produced by the Nd:YAG laser ( $j_{N}$ is a normalized amplitude of ion currents, recorded by different kinds of ICs).

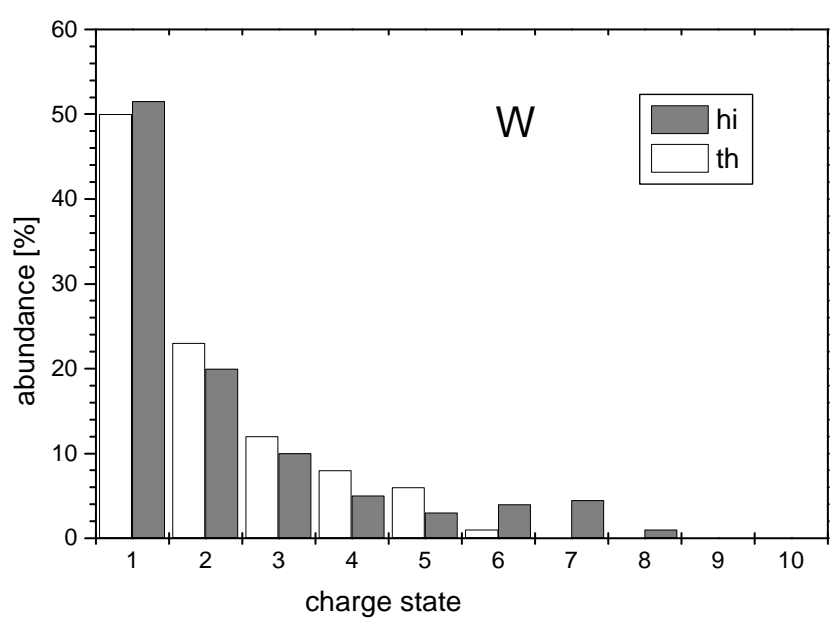

Figure 3. Abundance of $\mathrm{W}$ ions produced by the Nd:YAG laser at $E_{L} \sim 40 \mathrm{~mJ}$ (th) and at $E_{L} \sim 300 \mathrm{~mJ}$ (hi).

Both the PERUN and the PALS iodine laser systems were used to generate highly charged ions of the following medium- $\mathrm{Z}$ and high-Z elements (Al, Co, Ni, Cu, Ag, Sn, Ta, $\mathrm{W}, \mathrm{Pt}, \mathrm{Au}, \mathrm{Pb}, \mathrm{Bi}$ ) at their fundamental, as well as their $2 \mathrm{nd}$ and 3rd harmonic frequencies [1,12,20-23]. By changing either the laser pulse energy or the focal spot size (minimum focus spot position FP), the laser intensity on the target surface was varied from $1 \times 10^{13}$ to about $3 \times 10^{16} \mathrm{~W} / \mathrm{cm}^{2}$. Ion charge states slightly above $z=50+$ were recorded almost for all high- $Z$ elements ( $\mathrm{Ta}^{55+}$ was the maximum). The ion velocities (ion energies) ranged from about $2 \times 10^{6}$ up to $6 \times 10^{8} \mathrm{~cm} / \mathrm{s}$ (about $100 \mathrm{eV}-34 \mathrm{MeV}$ ) depending on the target element used and the laser intensity. Ion current densities, recalculated to a distance of $1 \mathrm{~m}$ from the target, reached up to tens of $\mathrm{mA} / \mathrm{cm}^{2}$ (tens of $\mathrm{kA} / \mathrm{cm}^{2}$ near the target), depending on the group of ions produced. The characteristics of the ions produced are summarized in Table 1 .

TABLE 1. Characteristics of iodine laser produced ions.

\begin{tabular}{|l|c|c|c|c|c|}
\hline Element & ${ }_{27} \mathrm{Co}^{59}$ & ${ }_{28} \mathrm{Ni}^{59}$ & ${ }_{47} \mathrm{Ag}^{108}$ & ${ }_{50} \mathrm{Sn}^{119}$ & $73 \mathrm{Ta}^{181}$ \\
\hline$z_{\max }$ & 25 & 26 & 38 & 38 & 55 \\
$E_{i \max }(\mathrm{MeV})$ & 2.6 & 2.5 & 3.6 & 3.5 & 22 \\
$j\left(\mathrm{~mA} / \mathrm{cm}^{2}\right)^{*}$ & 32.4 & 24.2 & 27.5 & 22.3 & 49.0 \\
\hline Element & $74 \mathrm{~W}^{184}$ & ${ }_{78} \mathrm{Pt}^{195}$ & $79 \mathrm{Au}^{197}$ & $82 \mathrm{~Pb}^{207}$ & $83 \mathrm{Bi}^{209}$ \\
\hline$z_{\max }$ & 49 & 50 & 51 & 51 & 51 \\
$E_{i \max }(\mathrm{MeV})$ & 4.9 & 8.5 & 4.8 & 5.1 & 5.1 \\
$j\left(\mathrm{~mA} / \mathrm{cm}^{2}\right)^{*}$ & 24.2 & 19.2 & 21.9 & 19.8 & 13.0 \\
\hline
\end{tabular}

* Recalculated to $100 \mathrm{~cm}$.

Charge spectra of Ta ions for both the $1 \omega$ and $3 \omega$ harmonic frequencies at various experimental conditions were measured, from which the charge-state distributions (CSD,
Fig. 4) and the charge-energy distributions (CED) were evaluated. The major portion of the ions (50-65\%) is composed of ions with charge states up to $10+$; the abundance 
of individual higher charge states is lower than $3 \%$. Increasing $E_{L}$ shifts $z_{\max }$ to higher values at the same laser frequency $(3 \omega)$ and also increases the amount of highly charged ions. Higher laser energy $E_{L}$ (laser intensity $I_{L}$ ) generally means higher plasma temperature, which implies higher mean charge state $z_{\text {mean }}$, higher $z_{\max }$ and higher $E_{i}$. An example of Ta ion charge-energy distributions for $E_{L}=215 \mathrm{~J}$ at $1 \omega$ is shown in Fig. 5.

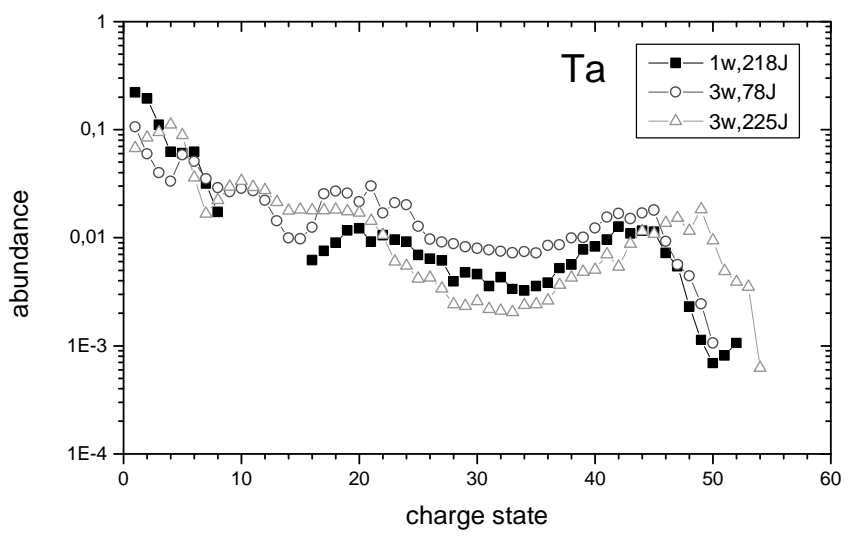

Figure 4. Abundance of the Ta ions produced by the fundamental $(1 \omega)$ and the 3rd harmonic $(3 \omega)$ frequencies of the iodine laser PALS at different laser energies $\left(E_{L}=78 \mathrm{~J}, 218 \mathrm{~J}, 225 \mathrm{~J}\right)$.

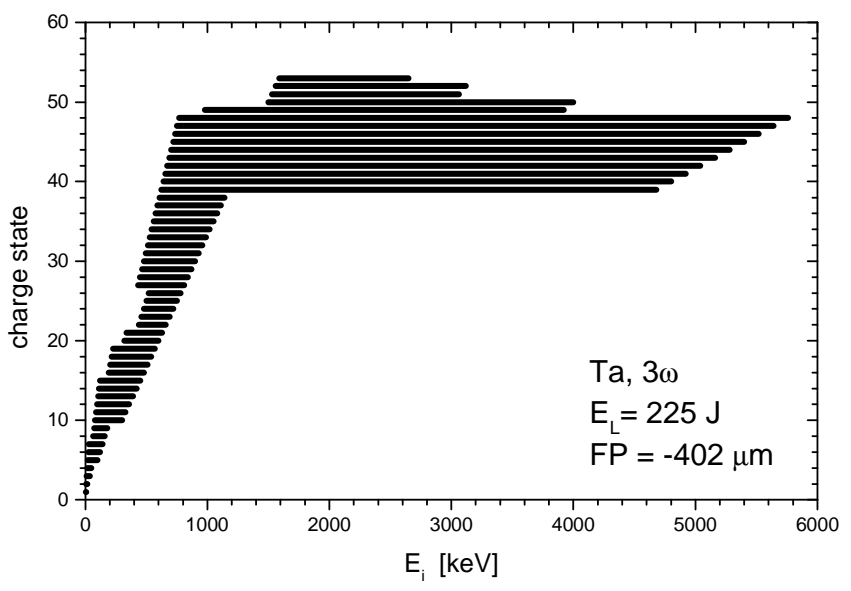

Figure 5. Charge-energy distribution of Ta ions produced by the 3rd harmonic frequency of the iodine laser PALS at the laser energy $E_{L}=225 \mathrm{~J}$ and at the minimum laser focal spot position $F P=-402 \mu \mathrm{m}$.

Generation of ions with charge states above $\mathrm{z}=45+\mathrm{de}$ pends on the absorbed laser intensity and on the "optimum" focus setting, which has been proven to be in front of the target surface [23]. It is defined as the position of the minimum laser focal spot (caustic) with regard to the target surface $F P$, for which the highest charge states, $z_{\max }$, are generated and consequently the highest amplitudes of the IC and IEA signals for the fastest Ta ion group are attained [12]. The convention used is that $F P=0$ when the minimum focal spot is located on the target surface, while $F P<0$ means that it is located in front of the target and $F P>0$ means that it is inside the target. The variation of $z_{\max }$ with $F P$, for $1 \omega$ and laser energy $E_{L}=215 \mathrm{~J}$, has a flat maximum at $z \sim 50+$ over a broad $F P$ range of about $900 \mu \mathrm{m}$, but is not symmetric around $F P=0$, where the nominal laser intensity is maximum (Fig. 6). The threshold laser intensity for $\mathrm{Ta}^{48+}$ ion production was $I_{L} \sim 5 \times 10^{15} \mathrm{~W} / \mathrm{cm}^{2}$ for $F P \sim+70 \mu \mathrm{m}$, but only $I_{L} \sim 3 \times 10^{14} \mathrm{~W} / \mathrm{cm}^{2}$ for $F P \sim+-850 \mu \mathrm{m}\left(I_{L}\right.$ was calculated according the linear approximation of the shape of the laser caustic [23]). The variation of $z_{\max }$ with $F P$ is narrower for $3 \omega$. Similar anomalous dependencies were recorded for the peak values of $\mathrm{v}, \mathrm{E}$ and $\mathrm{j}$ of the fast ion group(s) - see Fig. 7, a-c. Surprisingly, similar asymmetrical dependence on the $F P$ was also recorded for the diameter of the craters created on the target surfaces (which are not identical with the diameter of the laser spot at this location). The dependencies on $F P$ for $E_{L}=215 \mathrm{~J}$ and for $E_{L}=500 \mathrm{~J}$ show both clear minima for $F P<0$, as if the laser intensity minima were shifted [23].

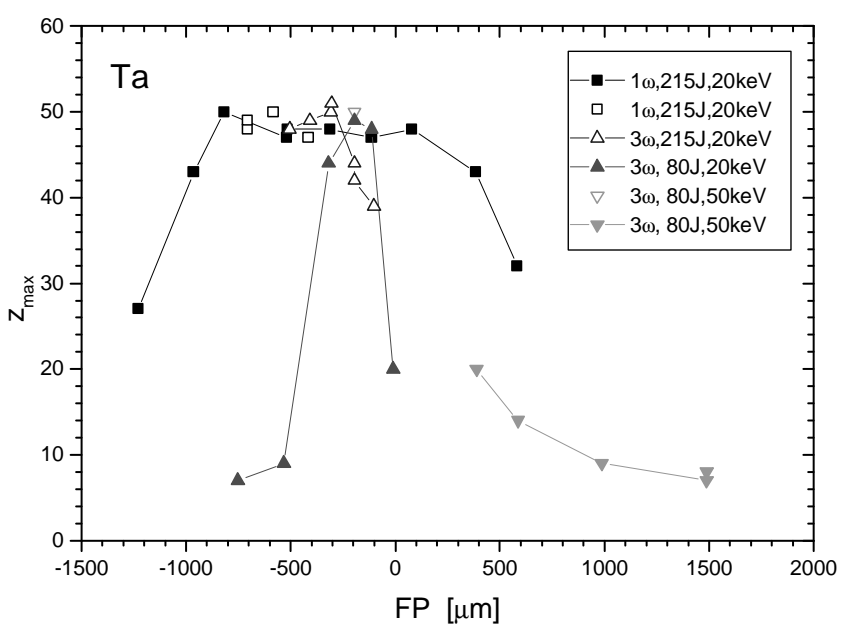

Figure 6. Dependence of the maximum charge state of Ta ions, $z_{\max }$, on the minimum laser focal spot position $F P$ at $1 \omega$ and $3 \omega$ for $E_{L}=80 \mathrm{~J}$ and $215 \mathrm{~J}$, and for two $E_{i} / z=20 \mathrm{keV}$ and $50 \mathrm{keV}$ (ion energy over charge ratio), for which the ion energy analyzer was adjusted.

This situation, with regard to the generation of highly charged ions, is similar to that where the conditions for the appearance of relativistic self-focusing are significantly improved by a short (ps) laser prepulse preceding the also short (ps) main pulse by about 100 ps [24]. A linear increase of the ion energy with increasing charge states represents, generally, the main ambipolar acceleration mechanism, which acts at different (low or high) plasma temperatures. The existence of an "optimum focus position" for generation of 

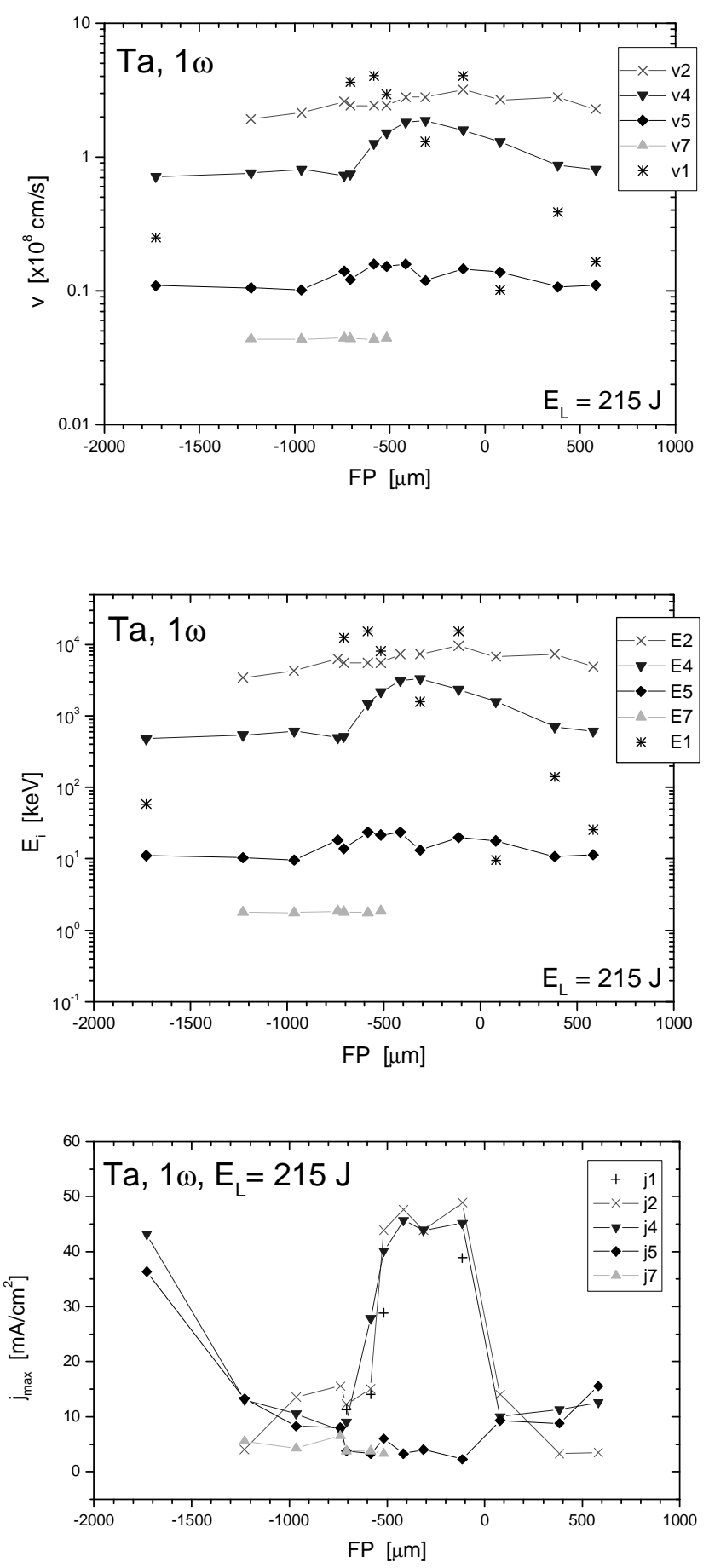

Figure 7. Dependence of peak velocities v, peak energies $E_{i}$ and maximum ion current densities $j_{\max }$ of different Ta ion groups (17) on the minimum laser focal spot position (with regard to the target surface), FP.

highly charged ions, which is found to lying in front of the target surface, indicates that the interaction of a long $\left(\tau_{L}>100 \mathrm{ps}\right.$ ) laser pulse (whose intensity is above a threshold $2 \times 10^{14} \mathrm{~W} / \mathrm{cm}^{2}$ with the self-generated plasma creates the conditions for relativistic self-focusing of the high intensity laser radiation and for the ion acceleration by nonlinear (ponderomotive) forces. This seems to be an indirect confirmation of the existence of the mechanism suggested by Hora [2],[24],[25]. The existence of two groups of ions (with two mechanisms of their production) may be deduced from Fig. 5.

\section{Conclusion}

Highly charged ions of high-Z elements, with charge states above $50+$ and with energies in $\mathrm{MeV}$ region, can be generated using the fundamental and lower harmonic frequencies of the iodine laser at high intensities above $I_{L} \sim$ $1 \times 10^{16} \mathrm{~W} / \mathrm{cm}^{2}$. Generally, the higher the laser energy (laser intensity) the higher the charge states and ion energies produced. Due to the convenient pulse length of the iodine laser (400 ps), a part of it may interact with the self-created expanding plasma. If the conditions for laser beam self-focusing are fulfilled, ions with maximum energies of $\mathrm{MeV}$ range and with charge states above $50+$ can be generated, starting at laser intensities above only about $2 \times 10^{14} \mathrm{~W} / \mathrm{cm}^{2}$

\section{Acknowledgments}

This work was supported by the Grant Agency of the ASCR (Grant A1010105), the European Union (Projects PALS/005 and PALS/006 under Contract HPRI-CT-199900053), the Ministry of Education of the Czech Republic (Project LN00A100), and the 5th National Committee of INFN (ECLISSE and PLAIA Projects).

\section{References}

[1] L. Láska, J. Badziak, F.P. Boody, S. Gammino, H. Hora, K. Jungwirth, J. Krása , P. Parys, M. Pfeifer, K. Rohlena, L. Torrisi, J. Ullschmied, J. Wołowski, and E. Woryna, Plasma Phys. Contr. Fusion 45, 585 (2003).

[2] H. Haseroth and H. Hora, Laser Part. Beams 14, 393 (1996).

[3] B. Yu. Sharkov, S. Kondrashev, I. Roudskoy, S. Savin, A. Shumshurov, H.Haseroth, H. Kugler, K. Langbein, N. Lisi, H. Magnusson, R. Scrivens, J.C. Schnuriger, J. Tambini, S. Homenko, K. Makarov, V. Roerich, A. Stepanov, and Yu. Satov, Rev. Sci. Instrum. 69, 1035 (1998).

[4] A. Balabaev, S. Kondrashev, K. Konukov, A. Lozhkin, B. Sharkov, A. Shumshurov, A. Charushin, K. Makarov, Yu. Satov, Yu. Smakovskii, O. Camut, J. Chamings, H. Kugler, and R. Scrivens, 10th ICIS 03, 2003, Dubna; Rev. Sci. Instrum. 75, 1572 (2004).

[5] S. Gammino, L. Torrisi, L. Ando L., G. Ciavola, L. Celona, L. Láska, J. Krása, M. Pfeifer, J. Wołowski, E. Woryna, P. Parys, and G.D. Shirkov, Rev. Sci. Instrum. 73, 650 (2002).

[6] S. Gammino, L. Torrisi, G. Ciavola, L. Ando, L. Celona, J. Krása, L. Láska, A.M. Mezzasalma, C. Gentile, A. Pizziotto, J. Wołowski, E. Woryna, D. Hitz, and G.A. Shirkov, J. Appl. Phys..

[7] V. Yu. Fominski, Vacuum 42, 73 (1991).

[8] F.P. Boody, R. Höpfl, H. Hora, and J.C. Kelly, Laser\&Part.Beams 14, 443 (1996). 
[9] L. Láska, J. Krása, K. Mašek, M. Pfeifer, K. Rohlena, B. Králiková, J. Skála, V. Peřina, V. Hnatowitz, E. Woryna, P. Parys, J. Wołowski, F.P. Boody, R. Höpfl, and H, Hora, Czech. J. Phys. 50/S3, 81 (2000).

[10] L.Torrisi, S. Gammino S., A.M. Mezzasalma, J. Badziak, P. Parys, J. Wołowski, E. Woryna, J. Krása, L. Láska, M. Pfeifer, K. Rohlena, and F.P. Boody, Appl. Surface Sci. 217, 319 (2003)

[11] F.P. Boody, in Beamed Energy Propulsion, AIP Conf. Proc. 664, 634 (2003).

[12] L. Láska, J. Krása, K. Mašek, M. Pfeifer, B. Králiková, T. Mocek, J. Skála, P. Straka, P. Trenda, K. Rohlena, E. Woryna, J. Farny, P. Parys, J. Wołowski, W. Mróz, A. Shumshurov, B. Sharkov, J. Collier, K. Langbein, and H. Haseroth, Czech. J. Phys. 46, 1099 (1996).

[13] K. Jungwirth, A. Cejnarová, L. Juha, B. Králiková, J. Krása, E. Krousk, P. Krupičková, L. Láska, K. Mašek, T. Mocek, M. Pfeifer, A. Präg, O. Renner, K. Rohlena, B. Rus, J. Skála, P. Straka, and J. Ullschmied, Physics of Plasmas 8, 2495 (2001).

[14] E. Woryna, P. Parys, J. Wołowski, and W. Mróz, Laser\&Part.Beams 14, 293 (1996).

[15] J. Krása, L. Láska, M.P. Stöckli, and D. Fry, Nucl. Instrum. Meth. B 173, 281 (2001).

[16] L. Láska, J. Krása, M.P. Stöckli and C.W. Fehrenbach, Rev. Sci. Instrum. 73, 776 (2002).

[17] L. Torrisi, L. Ando, S. Gammino, J. Krása, and L. Láska, Nucl.Instrum. and Methods B184, 327 (2001).
[18] L. Láska, J. Krása, M. Pfeifer, S. Gammino, L. Torrisi, L. Ando, and G. Ciavola, Rev. Sci. Instrum. 73, 654 (2002).

[19] A. Thum-Jäger and K. Rohr, J. Phys. D: Appl. Phys. 32, 2827 (1999).

[20] J. Krása, L. Láska, K. Mašek, M. Pfeifer, B. Králiková, J. Skála, P Straka, K. Rohlena, W. Mróz, E. Woryna, P. Parys, J. Wołowski, H. Haseroth, A.A. Golubev, and B. Yu. Sharkov, Laser\&Part.Beams 16, 5 (1998).

[21] J. Wołowski, J. Badziak, F.P. Boody, H. Hora, V. Hnatowicz, K. Jungwirth, J. Krása, L. Láska, P. Parys, V. Peřina, M. Pfeifer, K. Rohlena, L. Ryc, J. Ullschmied, and E. Woryna, Plasma Phys. Contr. Fusion 44, 1277 (2002).

[22] J. Wołowski, J. Badziak, F.P. Boody, S. Gammino, H. Hora, K. Jungwirth, J. Krása, L. Láska, P. Parys, M. Pfeifer, K. Rohlena, A. Szydlowski, L. Torrisi, J. Ullschmied, and E. Woryna, Plasma Phys.Control.Fusion 45, 1087 (2003).

[23] L. Láska, K. Jungwirth, B. Králiková, J. Krása J., M. Pfeifer, K. Rohlena, J. Skála, J. Ullschmied, J. Badziak, P. Parys, J. Wołowski, E. Woryna, L. Torrisi, S. Gammino, and F.P. Boody, 10th ICIS 03, 2003, Dubna; Rev. Sci. Instrum. 75, 1588 (2004).

[24] H. Hora, J. Badziak, F.P. Boody, R. Hpfl, K. Jungwirth, B. Králiková, J. Krása, L. Láska, P. Parys, V. Perina, M. Pfeifer, K. Rohlena, J. Skála, J. Ullschmied, J. Wołowski, and E. Woryna, Optics Communications 207, 333 (2002).

[25] T. Häuser, W. Scheid, and H. Hora., Phys Rev. A 45, 1278 (1991). 